\title{
Flipped classroom in a therapeutic modality course: students' perspective
}

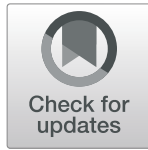

Dana Bates ${ }^{1 *}$ (D) and Genevieve Ludwig ${ }^{2}$

\author{
* Correspondence: dbates@pacificu. \\ edu \\ ${ }^{1}$ Pacific University, Hillsboro, USA \\ Full list of author information is \\ available at the end of the article
}

\begin{abstract}
The use of flipped classrooms has gained momentum and involves the instructor replacing the passive reception of material found in common lectures, so class time may be used for hands-on practical application, discussion, or assignments. The purpose of this paper is to explore students' perceptions of a flipped therapeutic modality course. Focus group interviews were conducted with sixteen participants (14 female, 2 male) who completed a therapeutic modality course. Data were collected through 4 focus group interviews, which were digitally recorded and transcribed. Data were analyzed to uncover dominant themes-first by organizing the data, then summarizing data into codes, and finally interpreting. Credibility was secured through peer review, member checks, and investigator triangulation. The analysis resulted in three common themes: the flipped classroom (1) was perceived as valuable by students, (2) led to active participation in class, and (3) helped students feel better prepared for the class. Athletic training students, particularly in a flipped therapeutic modality course, valued this pedagogical approach.
\end{abstract}

Keywords: Athletic training education, Classroom instruction, Computer-based learning, Blended learning

\section{Overview}

Athletic training educators are implementing a variety of pedagogical methods that promote more active learning environments. Active learning is defined as courserelated activities requiring students to do more than simply watch, listen, and take notes (Felder \& Brent 2009). Smith and Cardaciotto (2011) have stated that active learning can foster student engagement. A flipped classroom creates an active learning environment and has been used in many allied health settings including pharmacology (McLaughlin et al. 2014; Pierce \& Fox 2012; Giuliano \& Moser 2016; Koo et al. 2016), medicine (Young et al. 2014; Liebert et al. 2016; Moraros et al. 2015), dentistry (Park \& Howell 2015), nursing (Hanson 2016, Simpson \& Richards 2015), and athletic training (Heinerichs et al. 2016; Thompson \& Ayers 2015; Bates 2018). This pedagogical method uses a blended learning environment where content instruction occurs outside the class, while in-class time is spent on homework, discussion, interaction, or handson activities. A flipped classroom makes use of technology to move the formation of knowledge outside the classroom, allowing students time in class to apply their new

(c) The Author(s). 2020 Open Access This article is licensed under a Creative Commons Attribution 4.0 International License, which permits use, sharing, adaptation, distribution and reproduction in any medium or format, as long as you give appropriate credit to the original author(s) and the source, provide a link to the Creative Commons licence, and indicate if changes were made. The images or other third party material in this article are included in the article's Creative Commons licence, unless indicated otherwise in a credit line to the material. If material is not included in the article's Creative Commons licence and your intended use is not permitted by statutory regulation or exceeds the permitted use, you will need to obtain permission directly from the copyright holder. To view a copy of this licence, visit http://creativecommons.org/licenses/by/4.0/. 
learning through group work or through instructor-led activities that enhance the application of knowledge (Ronchetti 2010). This pedagogical approach allows in-class time to resolve misconceptions, foster the development of problem-solving skills, and facilitate collaboration amongst students.

In athletic training education, new accreditation standards have been developed and are currently being adopted. Currently, the education of future athletic trainers is also transitioning from two different routes (BS or MS) to single entry-level masters. While there is research on the flipped classroom at the undergraduate level, currently, there is no research in athletic training education at the graduate level. This is also the first study to explore the flipped approach in a therapeutic modality course. This study builds on and further expands our knowledge in the athletic training field as the entrylevel degree transitions to master's. The purpose of this study was to expand the existing research on a flipped pedagogy within athletic training education by exploring master's students' perceptions of a flipped classroom in a therapeutic modality course.

\section{Literature review}

Classrooms in higher education have begun to shift from the passive teaching style to a more engaged and active learning environment. The flipped classroom is one instructional method where students view online videos outside of class, while class time involves guidance by the instructor through assignments, scenarios, or group work (Ronchetti 2010). The flipped classroom has foundations in both constructivist and social learning theories (Moraros et al. 2015). The flipped classroom allows for the students to view learning as an active and social process. This blended learning has worked well in many classrooms as the students receive guidance from the instructor and the class time is spent "learning-by-doing" which supports a student's growth and educational advancement (Moraros et al. 2015). Research on the flipped classroom has demonstrated, through end of course surveys, students and faculty were satisfied with this pedagogical technique (Jeong et al., 2016; Giuliano and Moser 2016; Koo et al. 2016; Young et al. 2014; Liebert et al. 2016; Park \& Howell 2015; Simpson \& Richards 2015; Evseeva \& Solozhenko 2015; Gilboy et al. 2015; Della Ratta 2015; Weaver \& Sturtevant 2015; Mortensen \& Nicholson 2015). Other researchers have found the flipped classroom provided opportunity for faculty to give increased feedback (Young et al. 2014; Moraros et al. 2015; Mortensen \& Nicholson 2015), students were motivated to become self-learners and involved in the learning process (Simpson \& Richards 2015; McLaughlin et al. 2014; Moraros et al. 2015; Park \& Howell 2015; Evseeva \& Solozhenko 2015; Della Ratta 2015), and student performance outcomes were improved (McLaughlin et al. 2014; Pierce \& Fox 2012; Evseeva \& Solozhenko 2015; Weaver \& Sturtevant 2015; Mortensen \& Nicholson 2015).

Jeong et al. (2016) investigated the flipped classroom in science education using asynchronous video lectures with 153 general science students. During class time, the instructors utilized in-class numerical and non-numerical tasks, small group discussions, and case studies. Data were gathered through post-task questionnaires. Data demonstrated that students had positive perceptions of the flipped classroom. In this one study, $97 \%$ of participants considered watching the video lectures before attending class to be very meaningful in order to accomplish the proposed learning goals. Previous researchers have also supported these findings (Giuliano \& Moser 2016; Koo et al. 2016; 
Young et al. 2014; Park \& Howell 2015; Simpson \& Richards 2015; Evseeva \& Solozhenko 2015; Gilboy et al. 2015; Della Ratta 2015; Weaver \& Sturtevant 2015; Mortensen \& Nicholson 2015).

Researchers in medical education investigated the flipped classroom in masters-level introductory epidemiology course with 67 graduate students (Moraros et al. 2015). The course consisted of pre-class activities that included online video lectures and textbook readings. The in-classroom activities included a short quiz, practice problem sets, and student presentations. Surveys were administered at three different time points in the term to gather perceived effectiveness of the flipped classroom. Data demonstrated that students perceived more opportunity to engage in critical thinking and the instructor had more flexibility to cover a wider range and depth of material along with the ability to provide timely feedback and guidance to the students. Other researchers have also found that the flipped classroom provided faculty flexibility and timely feedback (Young et al. 2014; Mortensen \& Nicholson 2015).

Researchers in nursing education investigated the flipped classroom in a population health course which included 64 third-year public health students (Simpson \& Richards 2015). The online format for the content was voice over power-point, teaching videos, interactive online modules, and text readings. The instructors also implemented an out-of-class quiz that was to be completed prior to class as a way to ensure students prepared for their classroom work. The in-class activities included case studies, web quests, videos with response time, and group development presentations. Through the course evaluations, the researchers found students perceived the flipped approach created an active classroom which is further supported by other researchers (McLaughlin et al. 2014; Moraros et al. 2015; Park \& Howell 2015; Evseeva \& Solozhenko 2015; Della Ratta 2015).

While researchers have focused on perceptions, it is important to also investigate the impact on student's performance. A flipped approach was investigated in an 8-week pharmacology course with 71 participants, using performance on the final exam when compared to a non-flipped course as an outcome (Pierce \& Fox, 2012). Video podcasts of lectures were provided prior to scheduled classes. In class material included discussions and process-oriented guided inquiry learning activities. Data demonstrated students in the flipped class performed significantly better on the final exam when compared to the students in the traditional class. These findings have been further supported in other studies demonstrating the efficacy of active learning using the flipped classroom model improving student's outcomes (McLaughlin et al. 2014; Pierce \& Fox 2012; Evseeva \& Solozhenko 2015; Weaver \& Sturtevant 2015; Mortensen \& Nicholson 2015).

While the flipped classroom has been for the most part favorably received, some studies have found negative attitudes of this pedagogical approach (Simpson \& Richards 2015; Missildine et al. 2013; Moraros et al. 2015). Research (Moraros et al. 2015) found that students perceived the videos to be too long in duration. In this particular study, the videos were $60 \mathrm{~min}$. Simpson and Richards (2015) also found that participants perceived the flipped classroom led to excessive out of classroom work and a lack of contact with the faculty. Another common negative perception of the flipped classroom is the limitations of technology, such as poor quality of audio recordings (Simpson \& Richards 2015; Moraros et al. 2015). While the flipped classroom has received some negative perceptions, the overwhelming feedback from previous studies has demonstrated a favorable 
perception of the flipped approach (Jeong et al., 2016; Giuliano \& Moser 2016; Koo et al. 2016; Young et al. 2014; Liebert et al. 2016; Park \& Howell 2015; Simpson \& Richards 2015; Evseeva \& Solozhenko 2015; Gilboy et al. 2015; Della Ratta 2015; Weaver \& Sturtevant 2015; Mortensen \& Nicholson 2015).

Researchers in athletic training have investigated the flipped classroom with studies on student engagement (Heinerichs et al. 2016), rationale for the implementation of a flipped classroom to maximize student learning (Thompson \& Ayers 2015), and student perceptions in an orthopedic assessment course (Bates 2018). Heinerichs et al. (2016) was the first article in athletic training education that outlined the flipped approach with guidance on deliberate and strategic implementation for a blended course to create studentcentered, active-learning classrooms. An exploratory study (Thompson \& Ayers, 2015) investigating 17 students enrolled in an undergraduate orthopedic assessment course evaluated level of student engagement through self-reported daily questionnaires and weekly journals. Through mixed-method analysis, the researchers concluded that the flipped classroom was perceived favorably with content relevance and valued the student engagement and learning. Research (Bates, 2018) investigating 15 undergraduate students' perceptions of a flipped orthopedic assessment course demonstrated that students perceived the flipped classroom to be helpful, allowed repetition, initially created more work, and was self-paced. Of these three studies, two (Thompson \& Ayers 2015; Bates 2018) investigated a bachelor's orthopedic assessment course, while one (Heinerichs et al. 2016) provided a rationale for the implementation of a flipped classroom. Presently, no research has been published on master's athletic training pedagogy and the flipped classroom. As the entry-level degree for athletic training is transitioning to master's level only, research needs to be conducted at the master's level. Additionally, research (Pascarella et al., 1996) demonstrated higher critical thinking scores were based on the number of credit hours demonstrating critical thinking improves over time, further supporting the need for research at the master's level. The purpose of this study was to explore students' perceptions of a graduate flipped therapeutic modality course.

\section{Material and methods}

We employed a qualitative approach to further understand the students' perspectives on a flipped classroom. A qualitative approach allowed us to explore the experiences of the participants and to investigate students' perceptions of a flipped classroom at the master's level. This study aimed to further explore a flipped classroom and to enable us to describe the principle of the experience as perceived by the participants. This allows us to understand the practice of a flipped classroom as perceived by the participants (Creswell 2005).

For this study, a flipped classroom consisted of audio-recorded lectures that were reviewed outside of class to assist students with the formation of knowledge; class time was used to apply the new knowledge through group work or instructor-led learning activities (Ronchetti 2010). Focus group interviews with students allowed participants to express their thoughts about their flipped classroom experience. Focus group interviews, rather than one-on-one, were chosen due to the potential that some students would be hesitant to provide information through one-on-one interviews. The researchers encouraged all participants to provide information on their own experiences and were careful not to allow dominant students to control the conversation. All 
participants were notified that their responses would remain confidential. The interview protocol and consent form were reviewed and approved by the Institutional Review Board of the researcher's institution 132-17 dated on the 8th of December 2017. All participants signed a consent form before the start of their focus group interviews.

\section{Participants}

Participants were selected through a purposeful sample of graduates enrolled in a flipped class. A recruitment script was read in a spring term course asking for volunteers. Consent forms were handed out during this announcement for volunteers. Students who had signed consent forms were contacted by the principal investigator for scheduling of focus group interviews at a convenient time. Our sample consisted of 16 students $(14$ female, 2 male; mean age $=26.7)$ from the 2017 fall term who volunteered for the study (Table 1). Three participants had previous experience with a flipped classroom. Theoretical saturation, up to the point where additional data provided no new insight, was met at the fourth focus group interview (Creswell 2005). The principal investigator had heard the same comments repeatedly, and no further interviews were conducted.

\section{Intervention}

During the fall of 2017, a flipped classroom method was used with one 3.0 credit course, Therapeutic Modalities. This course was chosen to be flipped because the principal investigator, who was beginning employment at an entry-level master's athletic training program in the fall of 2017, had previously taught a flipped therapeutic modality course. The course, which met twice a week for $210 \mathrm{~min}$, used a combination of lecture and active-learning strategies (e.g., scenarios, group work, and think-pair-share). The online portion of the flipped classroom included eight audio-recorded lectures and

Table 1 Participant demographic information

\begin{tabular}{lll}
\hline Pseudonym & Age & Previous experience with flipped classroom \\
\hline Megan & 23 & No \\
Emma & 27 & Yes \\
Naomi & 28 & No \\
Sabrina & 24 & Yes \\
Nicole & 26 & No \\
Brooklyn & 23 & No \\
Lani & 26 & No \\
Kailey & 22 & No \\
Chloe & 23 & No \\
Lily & 22 & Yes \\
Bianca & No \\
Savannah & 27 & No \\
Lilah & 25 & No \\
Cash & 27 & No \\
Drake & 21 & No \\
Vanessa & 28 & No \\
\hline
\end{tabular}


pre-class quizzes. The 15-min, audio-recorded lectures were developed with Screencast-O-Matic (Screencast-O-Matic, Seattle, WA) using narrated screen capture, with relevant information displayed by PowerPoint. These chapter-specific audiorecorded lectures were embedded into the Moodle course website (version 3.4, Martin Dougiamas, Course Management System, Perth, Australia) and were provided as video links. The audio lectures were supplemental to the learning and allowed students to acquire content and knowledge before classroom application. These audio recordings were made available at the beginning of each content area and remained accessible until the end of the course so that students could continue to review them at any time. On average, each chapter-specific audio lecture took 2 to $3 \mathrm{~h}$ to prepare by the principal investigator. The principal investigator has over 6 years of experience flipping classrooms and recording audio lectures.

Supplemental literature (such as research and various therapeutic modality manuals) was available on Moodle for students prior to class sessions. An online quiz, with a single attempt permitted, was required to assess and ensure compliance for the pre-class work. The quizzes, designed for the lowest level of Bloom's taxonomy (Bloom 1984), included recall items and vocabulary from the audio lectures. The quizzes accounted for a total of 5\% of students' overall course grades. The correct quiz responses were made available after the due date so that students could use them as a study resource.

The didactic component of the class included lectures, labs, and active learning strategies. The lecture component was maintained in the course to expand on knowledge gained from audio-recorded lectures. The lectures focused on concepts students had not understood through the audio lectures or through the application of therapeutic modalities. The class also included a lab that allowed students to practice applying the various therapeutic modalities and setting parameters appropriate to the intended outcome. The active learning strategies utilized were scenario-based cases and think-pairshare. The think-pair-share activities were typically conducted at the beginning of class, during which students were asked to answer a question, posed by the principal investigator, to help them reflect on the audio-recorded lecture. The students would first think about the answer individually, then work in pairs to solve the problem, and lastly share their findings with the rest of the class. The scenario-based cases included the principal investigator giving the entire class a case with details on the extent and stage of the injury. Students would work individually at first to come up with appropriate therapeutic modalities to meet the specified treatment goals. Then, the students would work through the case in pairs, sharing what parameters they choose. Lastly, the groups would share with the entire class what modality and parameters were chosen to achieve the desired outcome.

\section{Data collection}

Data were collected through four focus group interviews, each with four participants ( $n$ = 16), with an interview guide in January and February 2018. The interview guide was designed to explore the students' perceptions of a flipped classroom and included open-ended questions which allowed for individual responses and gave the principal investigator opportunities to ask the students to describe the experience (Creswell 2005). 
Participants were asked to further clarify or describe any questions that may have been answered with a simple yes or no. The interview guide was based on the principal investigator's experience with qualitative research. An expert in athletic training education reviewed the guide for content, bias, and clarity. The principal investigator and expert in athletic training education met to discuss the interview guide, and grammatical edits were made based on feedback from the experienced qualitative researcher. The focus group interviews lasted $30 \mathrm{~min}$ on average. Focus group interviews were audio-recorded utilizing H4n Pro (version 4.0, Zoom, Hauppauge, NY).

\section{Data analysis and data credibility strategies}

The two researchers transcribed the audio recordings verbatim and then replayed the recordings to verify accuracy. The transcriptions and information were stored on a password-protected personal laptop. All participants received a transcript of the interview via e-mail for final review and to make sure their experiences with a flipped classroom had been captured correctly. Participants did not provide any feedback. Throughout the interview, notes were taken and were kept with the transcriptions in the principal investigator's locked office. Audio files were placed on an external hard drive at the end of the interview sessions. Records of interviews were kept in separate files and labeled with unique identification numbers.

We adopted a content analysis methodology approach to discover the perceptions of the participants (Erlingsson and Brysiewicz, 2007). The two researchers independently read transcript notes and interview notes to gain a general understanding of the perceptions of the participants. As the experiences of the participants were analyzed, the two investigators labeled each individual experience in codes and grouped the codes into categories. Several consensus meetings occurred between the two investigators throughout the analysis process to ensure consistent use of codes and categories. From the categories, themes emerged to express the underlying meaning of the flipped classroom. The Dedoose, a web-based research application (version 8.1.8, SocioCultural Research Consultants, Los Angeles, CA), was used to organize the direct quotes that demonstrated evidence to themes.

To ensure consistency and authenticity and to reduce bias, data credibility was established through member checks, peer review, and investigator triangulation. Member checking involved asking the participants to review transcript notes to confirm findings (Creswell 2005). After transcribing the interviews, all research participants received via e-mail a copy of the interview transcripts for review, clarification, and suggestions. This allowed participants to confirm, correct, or elaborate to ensure the accuracy of their comments. Peer review by a colleague who had no connection to the study served as an external check of the research process (Creswell 2005). The peer analyzed the data independently and also reviewed the interview guide and the validating codes. The colleague used an inductive approach that included reading the transcription notes and identifying codes and themes. Investigator triangulation involves multiple investigators collecting and analyzing data (Merriam 2009). In this study, the two researchers reviewed the data independently by reading and re-reading the transcription notes to determine themes. The two researchers completed two consensus meetings during the analysis process to agree upon findings. The researchers were also 
engaged in the data. Through these three processes of member checking, peer review, and investigator triangulation, credibility and validity were established.

\section{Results}

Themes indicated that participants in a flipped classroom found this approach to (1) be valuable, (2) lead to active participation in class, and (3) equip students to feel better prepared.

\section{Valuable}

Researchers found that participants in a flipped therapeutic modality course believed this educational technique to be a valuable tool. This theme-a flipped classroom serves as a valuable tool for these students-describes the belief that the flipped approach provides an additional resource. Participants mentioned the flipped classroom as a valuable tool and elaborated that this classroom approach led to additional resources, provided an alternative learning style, and allowed for replayability. While this course also required the use of a textbook and supplemental readings, the majority of participants stated that the flipped approach was a valuable resource in their learning.

Participants stated that the flipped approach in this therapeutic modality course provided additional resources that were useful in their studies. Brooklyn reflected that the flipped classroom was helpful for those that may be visual learners, noted, "I think it was the visual piece...seeing the video in front of me and then connecting it [the content], helped just connect things in my head." Many of the participants also stated they liked being able to go back to the recorded lectures before the test. Lilah stated that the audio lectures were helpful before taking a test, noting that "prior to the test it was a resource to go back to." Nicole also mentioned that the value of the flipped classroom was different from just having the book: "It [the audio lecture] was helpful for me instead of having to have my book in front of me and put all my attention on that [the book]. I can have the audio lecture on in the background if I'm doing something else." Savannah also commented on the variability of the resource and the ability to listen to the audio lecture in the car:

I would just have it playing in my car and listening to [it] a few times, then I'd get home and watch it, and then I go back to the reading. So, having the supplemental resource added to the homework and stuff and the lectures, I think that contributed toward my success in this class.

Several participants also stated that the flipped component was valued in their studies and allowed them to watch and listen multiple times. Emma mentioned that she liked the replay option with the flipped classroom: "I liked having the ability to replay it over and over again because I must have listened to those audio lectures maybe five times each." Chloe also commented on the replayability, stating, "You were hearing it over and over again, so it [the audio lecture] help[ed] with the test because I knew it."

The participants in this study described the flipped component of this one course to be a valuable tool in their therapeutic modality course. The participants believed the 
flipped classroom brought another resource into the course, addressed alternate learning styles, and the students could watch and listen several times.

\section{Active participation in class}

Participants stated that the flipped classroom allowed for more active participation in the classroom. The theme-active participation in class-emerged from the participants' perceptions that a flipped classroom led to more active participation. Several participants stated that the flipped classroom facilitated their participation, assisted with dialogue with the instructor, and helped with the development of questions. This therapeutic modality course included clinical case scenarios in the lab setting that were based off of material in the asynchronous lectures. This course includes a large portion of hands-on skill application. Chloe stated that through the flipped classroom, she could watch the audio lectures ahead of time and come to class ready to participate in clinical case scenarios:

I watched the video and take notes before class. Even if I hadn't gotten to the reading when I attended class, I knew what we were talking about, I knew what the lecture was going to be on, and I could participate and answer questions even though I hadn't done the reading.

Brooklyn also stated that the flipped class allowed for a more active class: "When I came to class...I could participate...I could answer questions...I could help the person next to me." Lani agreed that the flipped classroom allowed more participation, stating, "I feel like I was more willing to participate in your class."

Participants also stated that the flipped classroom allowed for more dialogue in class with the professor, providing more time to ask questions. Several participants stated that through watching the audio lectures, they developed questions ahead of time and then were able to ask those questions in class. Megan said that viewing the material ahead of time allowed her to develop questions, stating:

I even start writing my notes prior to class so when I go in, I already have my questions that I need to ask written down... because I find a lot of times that in the middle of class I need to ask the professor this and then I forget. So, having that general idea of what questions I need to ask helps my learning.

Lilah also discussed the benefit of being able to form questions based on the audio lectures, stating, "You may not always come up with the question while sitting in class. The audio lectures gave me the ability to pre-form questions."

The participants in this study found that the flipped approach in this therapeutic modality course increased their opportunities to apply knowledge to clinical case scenarios and in-class discussion. Many of the participants stated that watching the audio lectures before class was necessary for success-not only for the pre-class quizzes but also for participation in classroom discussion. Through the flipped classroom, the students perceived the course to be more active, leading to deeper engagement. 


\section{Better prepared}

Participants felt that through the flipped classroom they were better prepared for class. The theme-better prepared for class-emerged from the participant's perceptions related to the influence of the flipped classroom on the participants' ability to be prepared for class. Participants mentioned the flipped classroom better prepared them for class through helping them understand what would be covered in class, increasing their confidence for questions and how they felt less prepared for class if they had not followed the flipped approach. The majority of participants in this study stated they watched the audio lectures before coming to class. Megan stated she watched the audio-lectures the night before to prepare for class:

I liked being able to come into class prepared and having a general idea of what is going to happen that day so I can better use the night before...day before...to prepare myself for learning. I was going in with an open mind and a clear understanding of what we would be doing that day.

Students perceived that watching the audio-recorded lectures before class prepared them for what would be discussed in the classroom. Through this flipped format, they came to class knowing the content ahead of time and ready to learn. Brooklyn expanded on the idea of being prepared and how she liked the flipped approach:

The videos helped give some preface of what we are going to be learning...it was very beneficial for my learning. I had an idea of what we were going to talk about ahead of time. And then that way when you [the professor] asked us questions in class, I felt like I knew it and that gave me confidence...I understand this, and it just reiterated what I was learning and actually taking it in.

While the majority of the students did watch the audio lectures ahead of the content being covered in the didactic course, Bianca stated there were times she did not watch them ahead of time. In those circumstances, she mentioned feeling lost:

I actually didn't watch them ahead one time... and then I went to lecture and was lost. The first thing I thought was, 'Okay, I have to go back and listen to it' because I felt lost. I would just be confused and be needing more information...not having that access or knowledge before I walked in...It's hard and then I didn't understand. Watching it ahead of time I had a better understanding before I went into class.

The participants in this study perceived that the flipped classroom allowed time before class to view content, which they felt led to being prepared for class. The independent viewing of the videos before class time provided a way for the students to acquire and learn content for the class, which in turn led them to be better prepared for hands-on practice and in-class questions, assignments, and scenarios.

\section{Discussion}

Utilizing the flipped classroom in this therapeutic modality course replaced the traditional lecture-only classroom. The study's design was to introduce to master's students 
to a flipped classroom and discover their perspectives regarding this pedagogy. The students in this one course perceived the flipped classroom to be valuable, led to active participation, and better prepared them for class. Research in athletic training education is still lacking on the flipped approach. Previous research in athletic training education has only investigated undergraduate level flipped classroom (Bates, 2018; Thompson \& Ayers, 2015). The Commission on Accreditation of Athletic Training Education (CAATE) allows for programs to develop their own pedagogical philosophy with various methodologies to develop innovative, evidence-based programs which is currently transitioning the entry-level degree to master's only (CAATE, 2019). Heinerichs et al. (2016) provided a framework for creating a blended classroom with the flipped approach, but little research has been conducted in athletic training education. The goal of this research was to expand on the studies in athletic training specifically investigating if current research translates to athletic training education at the graduate level.

Research on the flipped classroom supports our study's findings that participants perceive this pedagogical approach to be beneficial and valuable (Thomspon \& Ayers, 2015; Zhai et al. 2017; Jeong et al. 2016; Baytiyeh 2017). Zhai et al. (2017) found that perceived value in a flipped classroom is positively associated with student satisfaction, prior learning experiences, personalized learning climate, and perceived quality of content. Another researcher (Baytiyeh 2017) found that students in a flipped classroom valued the learning process and experienced increased interest, self-efficacy, and enjoyment fostered by this learning method. Jeong et al. (2016) found $80 \%$ of participants in their study in the field of science believed that the flipped classroom provided a valuable learning experience. Thompson and Ayers (2015), in athletic training education, found a high level of support for the flipped classroom in an undergraduate orthopedic assessment course. While programs are transitioning to the master's level and curricula may need to be delivered in a condensed time frame, the flipped classroom may be a valuable pedagogical resource to supplement the students' learning. Our research on the flipped therapeutic modality course further supports the flipped classroom as a valuable pedagogical tool, especially at the graduate level.

Several studies support our findings that the flipped classroom leads to active participation (Pierce \& Fox 2012; Moraros et al. 2015; Simpson \& Richards 2015; Thompson \& Ayers 2015). Researchers in nursing education found that through comparing course evaluations of a flipped versus non-flipped class, the students perceived increased practical application of subject matter and greater use of multiple methods to involve them in learning (Simpson \& Richards 2015). The students in that study also pointed out that the flipped classroom led to an active learning environment which enhanced interaction and engagement. Thompson and Ayers (2015) further support these findings at the undergraduate level of athletic training. A study using mixed-methodology included students previewing specific material before class time while in-class work included peer-teaching through student-developed scenarios, practical lab activities, and case studies. Data were gathered through questionnaires and journals which demonstrated that students reported a high level of value in completing pre-class material to be successful in class and active participation in peer interactions. These findings (Simpson \& Richards 2015; Thompson \& Ayers, 2015) are further supported by researchers in pharmacology (Pierce \& Fox 2012), which demonstrated that flipped classrooms led to active engagement. In flipped classrooms, students spend time outside of class gaining 
knowledge on foundational concepts, making in-class time available for more active learning through problem-solving, discussion, experiments, and more interaction with peers and the instructor.

While faculty have been expecting students to read and prepare for class ahead of time, these traditional expectations have become obsolete. When students are motivated to study and prepare before classroom learning, they arrive to class ready for open discussion and to engage in group scenarios, leading toward an active classroom. The participants in our study perceived that through the flipped classroom, they were better prepared for class. Researchers support our study as several others have found that students felt more prepared in the flipped format as compared to traditional formats (Thompson \& Ayers 2015; Ihm et al. 2017; Subramaniam et al. 2018; Lucchetti et al. 2018). Thompson and Ayer (2015) found that a high percentage of students completed the pre-class work and also valued completing the material as necessary for successful participation during class. Researchers (Subramaniam et al. 2018) in medical education determined that $80 \%$ of the participants in a flipped classroom for high fidelity simulation training were more prepared than students who were limited to traditional learning sessions. When investigating a flipped classroom for pre-dental students, the students in the flipped component (as compared to non-flipped) felt more self-directed and better prepared before going to class (Lucchetti et al. 2018). The flipped classroom leads to students feeling more prepared for their learning in the classroom, which in turn leads to active participation in discussion, classwork, and scenarios which supports the research presented here.

A classroom that is active and also promotes collaboration among the faculty and students is critical to students' success. Kuh et al. (2006) have emphasized the importance of engagement through learning relationships that occur within active learning groups and through peer interactions. In a flipped classroom, faculty employ active learning strategies in the classroom while the students spend time outside of class watching the audio-recorded lectures. In our study, students were placed in learning groups that facilitated peer interactions. In a study about student-teacher interaction, Moran and Gonyea (2003) found that peer interactions had the most reliable predictive capacity for engagement and outcomes. Other researchers have also supported learning through student community experiences; such learning was positively associated with student gains in practical competence and personal and social development, and it also led to more significant effort and deeper engagement (Zhao \& Kuh 2004). The learning experience in a flipped classroom involves the passive lecture occurring outside the class, while active discussion and group work occur in the classroom. The time spent in the classroom can be used to further develop knowledge acquisition and skill practice through group work that is facilitated by the faculty.

In summary, participants in this particular flipped classroom perceived that this pedagogical approach led to a more active classroom, helped them be better prepared prior to the classroom, and served as a valuable resource in their learning. Current research in athletic training education (Heinerich et al. 2016; Thompson \& Ayers 2015; Bates 2018) has solely focused on the undergraduate courses. While the flipped classroom has been popular across health professions, athletic training education has not adopted the method as quickly. Through this study, the researchers have demonstrated the potential for the flipped classroom approach at the graduate level which builds on 
observation from its use in other health professions. This study further supports a growing body of educational research concerning active learning through various teaching methodologies.

\section{Limitations and future research}

Our study is limited to a small sample of students, at one university, and in one graduate course. The participants in this study comprised a convenience sample of students who participated in the flipped therapeutic modality course. We cannot generalize statements toward a broader population based on this one qualitative study of a flipped classroom. Future researchers investigating the flipped classroom should include more participants and represent a diverse group of participants. Additionally, this study used a qualitative inquiry to investigate students' perceptions, not the effectiveness of this pedagogical practice. Thus, future researchers should examine the flipped classroom through quantitative inquiry, including pre- and post-assessments, to measure the effects of a flipped classroom. While no one pedagogical model will meet all educational needs, future researchers could also investigate using the flipped classroom versus traditional classroom in athletic training.

\section{Conclusion}

Our findings suggest that a flipped classroom can create a classroom environment that is more active, in part due to students coming to class prepared and familiar with content ahead of time. This current study contributes toward the body of athletic training research investigating the flipped classroom. Higher education is seeing more courses flipped to promote student-centered active learning. Further evaluation of the flipped classroom in athletic training would expand the current research and investigate components that facilitate critical thinking not only in the classroom but beyond.

Acknowledgements

The authors would like to thank the graduate students who participated in this study.

Authors' contributions

Conceptualization: Dana Bates. Methodology: Dana Bates. Formal analysis and investigation: Dana Bates, Genevieve Ludwig. Writing original draft preparation: Dana Bates, Genevieve Ludwig. Writing and editing: Dana Bates, Genevieve Ludwig. The authors read and approved the final manuscript.

Funding

There was no funding for this research project.

Availability of data and materials

Data and material are not available as our consent forms did not include information regarding sharing data outside of the research study.

Competing interests

The authors declare that they have no competing interests.

Author details

${ }^{1}$ Pacific University, Hillsboro, USA. ${ }^{2}$ Boise State University, Boise, USA.

Received: 6 February 2020 Accepted: 6 July 2020

Published online: 17 July 2020

References

Bates, D. K. (2018). Flipped classroom in an orthopaedic assessment course: students' perspective. Athletic Training Education Journal, 13(4), 324-331. https://doi.org/10.4085/1304324.

Baytiyeh, H. (2017). The flipped classroom model: when technology enhances professional skills. International Journal of Information and Learning Technology, 34(1), 51-62. https://doi.org/10.1108/IJILT-07-2016-0025.

Bloom, B.S. (1984). Taxonomy of educational objectives. Book 1 cognitive domain. $2^{\text {nd }}$ ed. New York(NY): Longman. 
Commission on Accreditation of Athletic Training Education. (2019, July 15). Implementation and guide to the CAATE 2020 Professional Standards. Guide to 2020 Standards. https://caate.net/wp-content/uploads/2019/08/Guide-to-2020Standards-7-15-2019-2.pdf

Creswell, J. (2005). Qualitative inquiry and research design: choosing among five traditions. Thousand Oaks(CA): SAGE Publications.

Della Ratta, C. B. (2015). Flipping the classroom with team-based learning in undergraduate nursing education. Nurse Education, 40(2), 71-74. https://doi.org/10.1097/NNE.0000000000000112.

Erlingsson, C., \& Brysiewicz, P. (2017). A hands-on guide to doing content analysis. African Journal of Emergency Medicine, 7, 93-99. https://doi.org/10.1016/j.afjem.2017.08.001.

Evseeva, A., \& Solozhenko, A. (2015). Use of flipped classroom technology in language learning. Procedia Social and Behavioral Sciences, 206, 205-209. https://doi.org/10.1016/j.sbspro.2015.10.006.

Felder, R. M., \& Brent, R. (2009). Active learning: an introduction. ASQ Higher Education Brief, 2(4), 122-127.

Gilboy, M. B., Heinerichs, S., \& Pazzaglia, G. (2015). Enhancing student engagement using the flipped classroom. Journal of Nutrition Education and Behavior, 47(1), 109-114. https://doi.org/10.1016/j.jneb.2014.08.008.

Giuliano, C. A., \& Moser, L. R. (2016). Evaluation of a flipped drug literature evaluation course. American Journal Pharmaceutical Education, 80(4), 1-8. https://doi.org/10.5688/ajpe80466.

Hanson, J. (2016). Surveying the experiences and perceptions of undergraduate nursing students of a flipped classroom approach to increase understanding of drug science and its application to clinical practice. Nurse Education in Practice, 16(1), 79-85. https://doi.org/10.1016/j.nepr.2015.09.001.

Heinerichs, S., Pazzaglia, G., \& Gilboy, M. B. (2016). Using flipped classroom components in blended courses to maximize student learning. Athletic Training Education Journal, 11(1), 54-57. https://doi.org/10.4085/110154.

Ihm, J., Choi, H., \& Roh, S. (2017). Flipped-learning course design and evaluation through student self-assessment in a predental science class. Korean Journal of Medical Education, 29(2), 93-100. https://doi.org/10.3946/kjme.2017. 56.

Jeong, J. S., González-Gómez, D., \& Cañada-Cañada, F. (2016). Students' perceptions and emotions toward learning in a flipped general science classroom. Journal of Science Education and Technology, 25(5), 747-758.

Koo, C. L., Demps, E. L., Farris, C., Bowman, J. D., Panahi, L., \& Boyle, P. (2016). Impact of flipped classroom design on student performance and perception in a pharmacotherapy course. American Journal Pharmaceutical Education, 80(2), 1-9. https://doi.org/10.5688/ajpe80233.

Kuh, G., Kinzie, J., Buckley, J.A., Bridges, B.K., \& Hayek, J.C. (2006). What matters to student success: a review of the literature. National Postsecondary Education Cooperative. Accessed on February 25, 2019 at https://nces.ed.gov/npec/pdf/kuh_team_ report.pdf

Liebert, C. A., Lin, D. T., Mazer, L. M., Bereknyei, S., \& Lau, J. N. (2016). Effectiveness of the surgery core clerkship flipped classroom: a prospective cohort trial. American Journal of Surgery, 211(2), 451-457. https://doi.org/10.1016/j. amjsurg.2015.10.004.

Lucchetti, A. L. G., Ezequiel, O. S., Oliveira, I. N., \& Moreira-Almeida, A. (2018). Using traditional or flipped classrooms to teach "Geriatrics and Gerontology"? Investigating the impact of active learning on medical students' competences. Medical Teacher, 40(12), 1-9. https://doi.org/10.1080/0142159X.2018.1426837.

McLaughlin, J. E., Roth, M. T., Glatt, D. M., Gharkholonarehe, N., Davidson, C., Griffin, L., Mjmper, R. (2014). The flipped classroom: a course redesign to foster learning and engagement in health professions education. Academic Medicine, 89(2), 236-243. https://doi.org/10.1097/ACM.0000000000000086.

Merriam, S. (2009). Qualitative research: a guide to design and implementation. $2^{\text {nd }}$ ed. San Francisco(CA): Jossey-Bass.

Missildine, K., Fountain, R., Summers, L., \& Gosselin, K. (2013). Flipping the classroom to improve student performance and satisfaction. Journal of Nursing Education, 52(10), 597-599. https://doi.org/10.3928/01484834-20130919-03.

Moran, E., \& Gonyea, T. (2003). The influence of academically-focused peer interaction on college students' development. Access on February 25, 2019 at https://files.eric.ed.gov/fulltext/ED478773.pdf

Moraros, J., Islam, A., Yu, S., Banow, R., \& Schindelka, B. (2015). Flipping for success: evaluating the effectiveness of a novel teaching approach in a graduate level setting. BMC Medical Education, 14(27), 1-10. https://doi.org/10.1186/s12909-0150317-2.

Mortensen, C. J., \& Nicholson, A. M. (2015). The flipped classroom stimulates greater learning and is a modern $21^{\text {st }}$ century approach to teaching today's undergraduates. Journal of Animal Science, 93(7), 3722-3731. https://doi.org/10.2527/jas. 2015-9087.

Park, S. E., \& Howell, T. H. (2015). Implementation of a flipped classroom educational model in a predoctoral dental course. Journal of Dental Education, 79(5), 563-570.

Pascarella, E. T., Bohr, L., Nora, A., \& Terenzini, P. (1996). Is differential exposure to college linked to the development of critical thinking. Research in Higher Education, 37(2), 159-174.

Pierce, R., \& Fox, J. (2012). Vodcasts and active-learning exercises in a "flipped classroom" model of a renal pharmacotherapy module. American Journal Pharmaceutical Education, 76(10), 196. https://doi.org/10.5688/ajpe7610196.

Ronchetti, N. M. (2010). Using video lecture to make teaching more interactive. International Journal of Emerging Technologies in Learning, 5(2), 45-48.

Simpson, V., \& Richards, E. (2015). Flipping the classroom to reach population health: increasing the relevance. Nurse Education in Practice, 15(3), 162-167. https://doi.org/10.1016/j.nepr.2014.12.001.

Smith, C. V., \& Cardaciotto, L. (2011). Is active learning like broccoli? Student perceptions of active learning in large lecture classes. Journal of the Scholarship of Teaching and Learning, 11(1), 53-61.

Subramaniam, T., Valuyeetham, P. S., \& Siang, T. J. (2018). Students' feedback on effectiveness of combined flipped classroom and high fidelity simulated teaching on airway and ventilation during accident and emergency posting. Education in Medicine Journal, 10(2), 5-13. https://doi.org/10.21315/eimj2018.10.2.2.

Thompson, G. A., \& Ayers, S. F. (2015). Measuring student engagement in a flipped athletic training classroom. Athletic Training Education Journal, 10(4), 315-322. https://doi.org/10.4085/1004315.

Weaver, G. C., \& Sturtevant, H. G. (2015). Design, implementation, and evaluation of a flipped format general chemistry course. Journal of Chemical Education, 92, 1437-1448. 
Young, T. P., Bailey, C. J., Guptill, M., Thorp, A. W., \& Thomas, T. L. (2014). The flipped classroom: a modality for mixed asynchronous and synchronous learning in a residency program. Western Journal of Emergency Medicine, 15(7), 938-944. https://doi.org/10.5811/westjem.2014.10.23515.

Zhai, X., Gu, J., Liang, J. C., \& Tsai, C. C. (2017). An experiential learning perspective on students' satisfaction model in a flipped classroom context. Educational Technology and Society, 20(1), 198-210.

Zhao, C., \& Kuh, G. (2004). Adding value: learning communities and student engagement. Research in Higher Education, 45(2), $115-138$.

\section{Publisher's Note}

Springer Nature remains neutral with regard to jurisdictional claims in published maps and institutional affiliations.

Submit your manuscript to a SpringerOpen ${ }^{\odot}$ journal and benefit from:

- Convenient online submission

Rigorous peer review

- Open access: articles freely available online

- High visibility within the field

- Retaining the copyright to your article

Submit your next manuscript at $\boldsymbol{\nabla}$ springeropen.com 